\title{
A estética da recepção e as práticas de leitura do bibliotecário-indexador
}

Fabrício José Nascimento da Silveira:

\author{
Bibliotecário e mestrando em Ciência da \\ Informação pela Escola de Ciência da Informação \\ - ECI/UFMG.
}

Maria Aparecida Moura:

\author{
Doutora em Comunicação e Semiótica pela \\ PUC/SP. Professora Adjunta da Escola de Ciência \\ da Informação da UFMG.
}

A ciência da informação tem nos estudos sobre as práticas de leitura do bibliotecário-indexador um de seus mais profícuos campos de investigação. Verifica-se que a leitura realizada por este profissional o posiciona como mediador entre as diversas materialidades textuais contidas nos acervos e seus potenciais usuários. Com o objetivo de alargar o quadro explicativo desse fenômeno no contexto da ciência da informação, esse artigo recorre ao quadro teórico concebido pela estética da recepção para analisar a leitura desenvolvida por bibliotecários em contextos de representação temática. Para tanto, dialogase com conceitos fundamentais da estética da recepção tais como: horizonte de expectativa, efeito, emancipação e leitor implícito.

Palavras-chave: Leitura; Estética da recepção; Bibliotecário-indexador; Leitor implícito; Horizonte de expectativa.

\section{The aesthetic of reception and the practical of reading of librarian- indexer}

One of its richest fields of studies in Information Science is the reading practice of the librarian-indexer. It is verified that reading done by this professional places him/her as a mediator between the diverse textual materials contained in the library collections and its potential users. Aiming to further clarify this phenomenon 
in the context of Information Science, this article uses the theoretical framework conceived by the aesthetics of reception to analyze the reading performed by librarians in contexts of thematic representation. To do so, a dialogue is created with the basic concepts of the Aesthetics of Reception such as: expectation horizon, effect, emancipation and implied reader.

Key-words: Reading; Aesthetic of reception; Librarianindexer; Implied reader; Emancipation.

Recebido em 22.08.2006 Aceito em 25.10.2006

\section{Introdução}

A história da leitura é análoga à história de outras práticas culturais humanas, posto que se constitui através das várias configurações históricas que cada sujeito Ihes atribui. Sendo assim, toda prática de leitura se desenvolve e adquire sentido a partir de um determinado contexto histórico e espaço-temporal, conjugado com a subjetividade e os anseios específicos de cada leitor. Neste sentido, a leitura se apresenta como uma atividade interpretativa que possibilita a produção de múltiplos significados para um dado signo informacional, não se restringindo, pois, a apenas uma modalidade textual, ou seja, à decodificação de expressões rigidamente gravadas em um suporte material. Antes de sermos leitores de palavras, somos leitores do mundo, visto que desde o nascimento interagimos com os elos culturais que nos ligam a um dado tecido social. Somos leitores de estrelas, de sabores, sons e imagens que, ao adquirirem sentido, também outorgam sentido à vida daquele que com elas travam contato.

Isto posto, todo leitor deve ser compreendido como um sujeito autônomo que circula e se apossa livremente do texto, criando, a partir de seus anseios, habilidades intelectuais e lugar social, suas próprias interpretações para o signo que manipula.

Como outras práticas culturais, a leitura se tornou o foco central de inúmeros estudos que visam compreendê-la. Abordagens filosóficas, históricas ou literárias em diversos momentos tentaram lançar luzes sobre os muitos mecanismos envoltos em seu processo de efetivação.

Por acreditar que a leitura é uma prática que se constrói a partir do exercício interpretativo de sujeitos históricos que se localizam em um determinado contexto social e espaço-temporal, a estética da recepção se constitui como um dos esforços teóricos mais originais sobre a questão da leitura. Operando com conceitos como efeito, recepção, emancipação, horizonte de expectativa e leitor implícito, a estética da recepção tem por objetivo explicar sistematicamente o funcionamento deste fenômeno, e inseri-lo no contexto das práticas culturais de produção de sentido. 
Tratando os signos textuais como obras inacabadas e abertas a inúmeros olhares interpretativos, cujo sentido se consolida a partir da mescla entre o horizonte de expectativas dos autores e as possíveis significações estabelecidas por seus leitores, a estética da recepção atribui à leitura um efeito emancipatório que libera o leitor da busca por uma interpretação única, perfeita. Característica que permite a cada leitor imprimir sua marca interpretativa no texto com o qual interage.

É a partir deste enfoque que a estética da recepção surge como possibilidade para se ampliar o campo teórico da ciência da informação que investiga as práticas de leitura do bibliotecário-indexador. Isto porque, ao trabalhar com materialidades textuais diversas, o bibliotecário assume, a partir da especificidade de sua prática de leitura, a posição de mediador entre os signos informacionais presentes nos vários acervos com que lida, e os inúmeros usuários que os acessam. Contudo, o fato de ser um leitor mediador não o torna um leitor modelo, visto que sua prática profissional não se desvincula do movimento de apropriação, do desejo e da emoção que tal prática enseja.

Sendo um sujeito localizado em um contexto social, histórico e espaço-temporal específico, o bibliotecário também cria suas próprias estratégias de leitura, tendo-se em vista produzir representações simbólicas para os signos que manipula. Ou seja, a especificidade da leitura que este profissional executa não busca alcançar a mensagem original atribuída à obra no momento de sua concepção, mas sim, identificar enunciados capazes de representá-la e propiciar sua efetiva recuperação. Por isso, sua atividade interpretativa possui o mesmo grau de liberdade criadora de leitores comuns.

Compreendendo a leitura como uma prática cultural que se desenvolve a partir da interação entre a subjetividade de cada leitor e seu lugar social pretendemos analisar as estratégias de leitura utilizadas pelos bibliotecários em seu fazer profissional, a partir das proposições teóricas da estética da recepção, como possibilidade para se ampliar o referencial explicativo da ciência da informação que investiga este campo teórico.

\section{Leitura: prática cultural de produção de sentido}

Embora seja vista como um elemento essencial para que o homem construa e efetive as relações que estabelece com o meio no qual se insere, a leitura não se configura como um ato natural, mas antes, como uma prática histórica, social e culturalmente demarcada. É a prática por meio da qual sujeitos comuns interpretam e atribuem significados múltiplos ao mundo que os cerca. É uma arte investigativa que "quase não deixa traços visíveis nem garantias contra a usura do tempo, mas ação produtora que em cada um dos seus encaminhamentos e de fazeres, ao mesmo tempo alteram e conferem existência ao texto". (CHARTIER; HÉBRARD, 1998, p. 32). É, enfim, apropriação, recriação, uma arte de fazer que não se restringe a um único conceito, mas sim, a um conjunto de práticas difusas e em permanente transformação. 
Desta forma, pode ser classificada como um processo de tradução no qual se transpõe para a linguagem verbal os diversos signos que permeiam nossas relações de interação e comunicação com o mundo. Embora esteja intimamente relacionada com a escrita, efetuamos, mesmo que inconscientemente, diversos outros tipos de leitura. É o caso da leitura que o músico faz de uma partitura, traduzindo-a em sons e sentimentos; a leitura das estrelas feita pelos astrônomos; ou a leitura dos oráculos que prevêem o futuro a partir de movimentos naturais. Todos eles dividem com os leitores de palavras os segredos de atribuir sentido e viabilizar os processos de interação e comunicação.

Por ser uma prática interpretativa, a leitura não deve ser vista como uma recepção imposta de conteúdos objetivos ou como um ato passivo de sujeição ao texto. Todo leitor, como nos aponta Michel de Certeau (1994) caça em terras alheias, demarca com os olhos, com o dedo, com o franzir das sombrancelhas, com o sorriso, seus caminhos em busca do sentido. Sob a contingência, sem dúvida, e no espaço próprio do texto, ele elabora - como quer ou como pode - sua leitura do texto: um novo texto. (CHARTIER e HÉBRARD, 1998, p. 33). Toda leitura é, então, um processo voluntário da inteligência, por meio do qual produzimos e sobrecodificamos sentidos e significados.

No entanto, mesmo sendo uma prática que se liga à inteligência, a leitura não é apenas uma operação intelectual abstrata, ela é também o uso do corpo, uma inscrição dentro de um espaço histórico-temporal e uma relação dos leitores consigo mesmo e com os outros. A leitura de qualquer texto é, portanto, um processo de construção cultural e histórica que se efetiva a partir da mescla entre as condições materiais destinadas à sua produção e disponibilizarão, e a subjetividade e o lugar em que cada leitor se encontra no momento de executá-la. Nenhum leitor é confrontado com textos abstratos, ideais ou desligados de uma materialidade espaço-temporal, eles manipulam objetos, ouvem palavras cujas modalidades governam a leitura e a escrita. Fazendo isso, comandam a possível compreensão e apropriação do texto, posto que, "toda história das práticas de leitura é, portanto, necessariamente uma história dos objetos escritos e das palavras leitoras". (CAVALLO e CHARTIER; 2002, p. 6).

O leitor é, pois, um sujeito autônomo capaz de construir sentidos e imprimir sua marca interpretativa no texto que sobrecodifica. Leitor é aquele que se apossa do texto para dotá-lo de existência, visto que todo signo passível de leitura se abre a uma infindável possibilidade de significações.

Por sua vez, nenhum texto se apresenta como uma obra hermeticamente fechada à procura de um sujeito capaz de restabelecer o significado primeiro que possibilitou sua criação. É antes, um constructo que adquire sentido mediante a interação dos anseios e da capacidade subjetiva de seus leitores, com o contexto espaço-temporal onde se inserem, e com a especificidade das características que the foram atribuídas no momento de suas concepção. 
É por este motivo que explicar as práticas de leitura requer compreendê-las como um constructo sócio-cultural que adquire sentido a partir da urdidura de inúmeras variáveis que em nenhum momento se isolam.

\section{A estética da recepção e a emancipação do leitor implícito}

A história da leitura é marcada por inúmeras tentativas de explicar as dinâmicas envoltas em seu processo de efetivação. Estudos com viés filosófico, teológico, hermenêutico, histórico, sociológico ou literário lançaram luzes sobre as diversas possibilidades de interação entre leitores e signos textuais.

Inserindo-se neste panorama, a estética da recepção se apresenta como um dos esforços interpretativos acerca da leitura e das relações que se estabelecem entre texto, autor e leitor, mais originais e profícuos dos últimos séculos. Isto porque, tal corrente teórica entende as várias materialidades significativas como um complexo que adquire sentido a partir da relação dialética que se instaura entre o autor, a obra e seus possíveis leitores. Desta forma, defende que toda atividade interpretativa se constitui mediante o processo de interação entre a subjetividade do leitor e as condições sócio-históricas na qual determinado signo se originou.

A estética da recepção teve início em 1967 na Universidade de Constança na Alemanha. Naquela ocasião, Hans Robert Jauss proferiu a conferência intitulada. O que é, e com que fim se estuda história da literatura?, conferência que posteriormente se denominou: A história da literatura como provocação à ciência literária.

Influenciado pela análise hermenêutica da obra de arte efetuada por Gadamer, Jauss propõe, a partir deste texto, uma mudança metodológica a respeito das abordagens interpretativas de obras artísticas. Sugere que o foco central de toda interpretação textual deve recair sobre o leitor e seus processos de recepção e não exclusivamente sobre o autor e os mecanismos envoltos na concepção dos mesmos. Ao fazer isso, Jauss atribui à hermenêutica o papel de intérprete da história, reconhecendo nela as bases do conhecimento do texto, fato este que, segundo o autor, permite recuperar a imagem do leitor como um produtor de interpretações e significações válidas.

Jauss acredita que todo signo passível de leitura não se configura apenas como uma reprodução, um reflexo dos eventos sociais que possibilitaram sua concepção. São, antes, um constructo social e cultural que, a partir de sua historicidade, desempenha um papel ativo na produção das possíveis interpretações de cada leitor, na medida em que envolve e ativa as estruturas intelectuais, emotivas e sensoriais dos mesmos.

O leitor de Jauss é, então, uma figura histórica que respeita a história do signo que lê, mas que ao mesmo tempo promove uma ruptura com as leituras feitas até aquele momento, empreendendo sua própria 
interpretação, sua marca pessoal na obra que lhe é apresentada. Isto posto, torna-se possível inferirmos que a concepção de leitor de Jauss se baseia em duas categorias essenciais:

A de horizonte de expectativa, misto dos códigos vigentes e da soma de experiências sociais acumuladas; e o conceito de emancipação, entendido como a finalidade e efeitos alcançados pela arte, que libera seus destinatários das percepções usuais e confereIhes nova visão da realidade. (ZILBERMAN, 1989, p. 49-50).

Portanto, para o referido autor, todo ato de recepção, julgamento estético ou interpretação, por mais espontâneo que seja sua expressão, advém de uma câmara de ecos onde ressoam os pressupostos históricos, sociais ou técnicos que possibilitam sua efetivação.

Neste sentido, ao estabelecer que o signo lido provoca, a partir de sua historicidade, uma reação, um efeito em seus leitores, Jauss atribui à leitura uma natureza emancipatória, segundo a qual a experiência da leitura libera o leitor de adaptações, prejuízos e apertos de sua vida prática, atribuindo-Ihe a possibilidade de se emancipar e empreender novas percepções, sentidos e interpretações para o mundo no qual habita.

Enquanto Jauss se preocupa em entender como se dão os processos de recepção das obras de arte, Wolfgang Iser, outro importante teórico da estética da recepção, se preocupa com o efeito que cada obra causa em seus receptores, vale dizer, leitores. Iser distingue, então, duas modalidades de interação entre a obra e o leitor: de um lado temos o efeito que toda obra provoca em seu leitor; e de outro, a recepção, processo histórico que se institui a partir das diferentes interpretações que cada leitor lhe impõe.

Acreditando que os signos passíveis de leitura estão abertos a múltiplas interpretações, visto não serem concebidos como um espelho da realidade, Iser chama o leitor a participar do processo de criação dos mesmos. Tal participação, por sua vez, não se limita ao mero preenchimento dos vazios que toda obra traz consigo, é antes, o processo de constituição da própria obra que, graças à atuação do leitor, passa de "mero artefato artístico a objeto estético, passível de contemplação, entendimento e interpretação". (ZILBERMAN, 2001, p.51.). Isto porque, tais vazios provocam estímulos que viabilizam a impressão, através da força imaginativa dos leitores, de vários sentidos interpretativos para a obra que manipula.

Além disso, ao ser influenciado por Ingarden, Iser concebe o conceito de estrutura de apelo do texto que determina que o mundo imaginário, ao ser representado em uma obra, mostra-se esquematizado, por isso incompleto. Apresentando, pois, vários pontos de indeterminação, vazios, lacunas que dependem da interferência dos leitores para adquirirem sentido. Sentido este que, segundo o referido autor, não é uma mensagem universal a ser extraída do texto por um leitor competente, um leitor implícito capaz de atingir a completude significativa da obra lida, é antes, uma interpretação mutável em virtude da historicidade própria da obra e das várias leituras que a mesma sofre. Isto porque: 
Quando lemos, nossa expectativa é função do que já lemos - não somente ao texto que lemos, mas em outros textos -, e os acontecimentos imprevistos que encontramos no decorrer de nossa leitura obriga-nos a reformular nossas expectativas e a reinterpretar o que já lemos, tudo o que já lemos até aqui neste texto e em outros. A leitura procede, pois, em duas direções ao mesmo tempo, para frente e para trás, sendo que um critério de coerência existe no princípio da pesquisa do sentido e das revisões contínuas pelas quais a leitura garante uma significação totalizante à nossa experiência. (COMPAGNON, 2003, p. 149).

Toda prática de leitura é, então, um grande percurso em busca de se atribuir sentido ao texto. Por isso, nenhum signo textual pode ser apreendido todo de uma só vez. O leitor é um viajante que desvenda, ao longo do processo de leitura, os sentidos, os significados, as múltiplas possibilidades interpretativas que a obra lhe oferece. Neste caso, nenhuma obra se apresenta por completo, mas se evidencia durante a travessia, durante as intervenções de seus leitores. Eis aqui, o grande paradoxo da leitura:

Admite-se comumente que ler é decodificar: letras, palavras, sentidos e estruturas, e isso é incontestável; mas acumulando as decodificações, já que a leitura é, de direito infinita, tirando a trava do sentido, pondo a leitura em roda livre (o que é sua vocação estrutural), o leitor é tomado por uma intervenção dialética: finalmente ele não decodifica, ele sobrecodifica; não decifra, produz, amontoa linguagens, deixa-se infinita e incansavelmente atravessar por elas: ele é essa travessia. (BARTHES, 1988, p. 51).

Se toda obra só se efetiva a partir das intervenções de seus leitores, a noção de um leitor ideal é, para Iser, uma falácia, uma impossibilidade estrutural. Isto porque, um leitor ideal é aquele que possui o mesmo código que o autor; é aquele que tem as mesmas intenções que se manifestam no processo criativo. Desta forma, para o referido autor, "o leitor ideal é, à diferença de outros tipos de leitores, uma ficção". (ISER, 1996, v.1, p. 66).

Em contraponto à idéia de leitor ideal, Iser propõe o conceito de leitor implícito. Conceito percebido, simultaneamente, como uma estrutura textual e como um ato estruturado. O leitor implícito de Iser não tem uma existência real, nem se funda em um substrato empírico, mas sim, na própria estrutura do texto. Isso significa que as condições necessárias à existência e atualização do texto se inscrevem em sua própria construção. Sendo assim, o conceito de leitor implícito enfatiza as estruturas de efeito do texto, cujos atos de apreensão relacionam o receptor a ele.

Portanto, o conceito de leitor implícito de Iser postula que o efeito condicionado pela obra, apesar de oferecer uma orientação prévia quanto às formas de lê-las e quanto ao significado a ser apreendido, não reduz o leitor a um sujeito passivo à caça de uma mensagem original, mas propicia a este o direito de estabelecer inúmeras interpretações e imprimir na obra lida, sua marca criativa. Sendo assim, para este autor: 
A recepção, no sentido estrito da palavra, diz respeito à assimilação documentada de textos e é, por conseguinte, extremamente dependente de testemunhos, nos quais atitudes e noções se manifestam enquanto fatores que condicionam a apreensão do texto. Ao mesmo tempo, porém, o próprio texto é a prefiguração da recepção, tendo com isso um potencial de efeitos cujas estruturas põem a assimilação em certo curso e a controlam até certo ponto. (ISER, 1996, v. 1, p. 7).

É, portanto, a partir desse aporte teórico que podemos caracterizar a leitura como uma prática cultural que encerra em si modos, ritmos, intensidades e desejos que variam de texto para texto e de leitor para leitor, cujos sentidos e valores são determinados pelas múltiplas possibilidades de interação entre a obra e seus vários interlocutores.

\section{Leitor-mediador: entre a interpretação e a representação}

Conforme vimos anteriormente, a leitura deve ser compreendida como uma atividade multisensorial. Isto implica necessariamente na capacidade adquirida pelo leitor de transitar, de modo proficiente e colaborativo, entre distintas linguagens. Ocorre, no entanto, que a esta exigência se somam o domínio do conteúdo disponibilizado e as condições de realização da leitura.

A leitura profissional, dentre as quais se insere aquela realizada por bibliotecários, acontece em meio a complexidades. Tais complexidades dizem respeito ao esforço tradutório de interpretar e transitar entre signos no qual o referido ator, nem sempre é considerado como o interlocutor prioritário.

Nas ações de leitura profissional, o leitor-mediador é compelido a se apropriar de um conteúdo informacional denso, como se fora o leitor final. Nestas circunstâncias, o mesmo elabora sínteses informacionais (resumos, indexação) que têm por propósito demarcar a centralidade daquele item em relação aos demais. Entretanto, esse gesto se torna complexo em virtude de ter como exigência a performance de um leitor hábil no domínio proposto, visto que, no mais das vezes, é um gesto intenso, afirmativo e com poucas possibilidades de revisão.

Deste modo, a atividade de leitura para fins de representação temática é conduzida por rígidos padrões técnicos e por informações rarefeitas, do ponto de vista de quem realiza a mediação. O gesto de leitura realizado com esse fim tenta articular, e por vezes conter, o movimento natural de apropriação sígnica a àquele que visa sinalizar uma dada informação aos sujeitos para os quais se dirige.

Mediar o acesso à informação a partir da coleta, armazenamento, organização, leitura e representação da mesma é uma das funções que demarca o fazer profissional dos bibliotecários. Ao se posicionar como um mediador, o bibliotecário assume a função de um intérprete que trabalha sobre materialidades discursivas diversas, com o objetivo de criar, a partir de suas interpretações, representações condensadas dos inúmeros conteúdos de cada item informacional que se encontra inserido em seu acervo, na tentativa de facilitar o acesso aos mesmos. 
Diferentemente das práticas de leitura até então apresentadas, essa modalidade não requer, necessariamente, uma leitura integral de todo o documento, nem mesmo uma interação prazerosa entre leitor e texto. No entanto, não dispensa a interpretação e os processos de re-significação e atribuição de sentido e valor que toda prática de leitura prevê.

No contexto das instituições enfatizadas pela moderna sociedade da informação, o bibliotecário tornou-se, pois, leitor mediador; intérprete que trabalha sobre materialidades discursivas variadas, com o objetivo de criar, a partir de suas interpretações, representações condensadas de objetos informacionais com efeito de completude.

A leitura técnica, consolidada no âmbito da profissionalização da leitura, consiste na abordagem global dos itens informacionais, e tem por objetivo recolher os dados que permitirão o estabelecimento da representação destes itens nos sistemas de informação. Este procedimento técnico aciona dois outros: a análise de assunto e a indexação, que tornam possíveis a identificação, a extração dos termos referenciais e a tradução dos mesmos, em itens de representação, que adquirem pertinência por intermédio de uma linguagem de indexação.

Com vistas a reduzir a ambigüidade da atividade de representação informacional, o bibliotecário tem ao seu dispor normas e padrões nacional e internacionalmente consolidados, bem como ferramentas específicas (linguagens de indexação e os esquemas de classificação) que visam contextualizar o domínio no qual se insere 0 item a ser representado.

Entretanto, dada à complexidade do gesto de leitura realizado nestes contextos e à variedade dos atuais objetos de leitura, tais ferramentas de contextualização não são mais suficientes para balizar a atividade de representação informacional.

Hoje, em função das inovações tecnológicas no campo da produção textual, o bibliotecário é desafiado a representar objetos informacionais cujo conteúdo temático e estrutural do texto é transitório. Além disso, as interfaces temáticas multidisciplinares são cada vez mais evidentes, exigindo uma interação ainda mais intensa do leitor-mediador com o contexto de recepção das informações. Nesse sentido, esta prática de leitura adquire contornos cada vez mais contingentes, visto que, se por um lado esse leitor é paradoxalmente desencorajado a se apropriar dos conteúdos lidos, por outro, a leitura realizada já não pode mais se circunscrever aos limites da leitura técnica.

Tais limites se devem, em parte, ao ritmo acelerado e às tensões empreendidas pela revolução da textualidade digital.

Segundo Chartier (2002) os textos eletrônicos introduziram complexidades que sinalizam para diferentes futuros. Neste sentido, 0 referido autor salienta que tais complexidades podem ser visualizadas a partir de três características básicas, são elas:

- A consolidação de comunidades separadas e cimentadas pelo uso específico das novas técnicas,

- O controle centralizado nas mãos das empresas de multimídia,

- A constituição de um público universal. 
Todos os elementos assinalados acima, incidem de forma direta ou indireta sobre a atividade da leitura profissional. Para Chartier (2002), estes novos elementos passaram a exigir novas categorias estéticas, administrativas e biblioteconômicas, na medida em que se consolidaram sob a égide da cultura escrita. Nesse sentido, impõe-se a redistribuição de papéis no contexto da economia da escrita. Sobretudo porque:

A originalidade e importância da revolução digital apóiam-se no fato de obrigar o leitor contemporâneo a abandonar todas as heranças que o plasmaram, já que o mundo eletrônico não mais utiliza a imprensa, ignorar o "livro unitário" está alheio à materialidade do códex. E ao mesmo tempo uma revolução da modalidade técnica da produção do escrito, uma revolução das estruturas e formas mais fundamentais dos suportes da cultura escrita. Daí a razão do desassossego dos leitores, que devem transformar seus hábitos e percepções, e a dificuldade para entender uma mutação que lança um profundo desafio a todas as categorias que costumamos manejar para descrever o mundo dos livros e a cultura escrita. (CHARTIER, 2002, p. 24).

A exigência de renovação das categorias para se pensar a leitura na contemporaneidade sinaliza para o fato de que, se já era complexo pensar a mediação na cultura escrita, o que dizer então da mediação realizada em contextos de acentuada virtualização?

\section{Objetos de leitura efêmeros e a permanência do bibliotecário-indexador}

Sendo a leitura muito mais que decodificação de palavras inscritas em um suporte material, percebemos que a ciência da informação passou, nos últimos anos, a também se dedicar aos estudos que visam compreender os impactos e implicações das inovações tecnológicas na atividade de representação da informação.

Se até o surgimento do computador e da internet a leitura era sinônimo de livro, e o leitor era aquele que decifrava palavras. Verifica-se hoje, que o ato de ler não se restringe apenas à decodificação de letras, visto que tal prática incorpora cada vez mais as relações entre palavras, sons e imagens. Com isso, o principal desafio que se impôs à ciência da informação foi saber se haveria a possibilidade de se instaurar uma completa automação para o processo de representação da informação, em relação às atividades de caráter intelectual realizadas por seres humanos.

O debate em torno desse desafio fez surgir inúmeras abordagens teóricas e distintas experimentações práticas de caráter tecnológico. Este movimento de idéias tornou ainda mais premente e evidente a natureza interdisciplinar da ciência da informação.

Como ganho institucional, obteve-se a consolidação de ferramentas tecnológicas que dotaram de leveza, regularidade e sofisticação as atividades de representação da informação. Contudo, a almejada 
autonomia do processo de representação informacional ainda continua a mobilizar os debates e a buscar técnicas e ferramentas tecnológicas que auxiliem na execução do referido processo.

A popularização da internet nos anos 90 potencializou significativamente os debates e ampliou a crença de que a recuperação automática resolveria o problema da recuperação da informação. Evidentemente as inovações ampliaram o poder de varredura do sistema informacional para fins de recuperação da informação, mas também evidenciaram, em proporções gigantescas, a dificuldade de recuperação da linguagem natural em sistemas informacionais.

Deste modo, e diante do impasse criado, verifica-se a busca por uma terceira via possível. No que concerne ao processo de recuperação intelectual da informação, constata-se que o olhar humano, feito por profissionais da leitura, tais como o bibliotecário-indexador, ainda é imprescindível para garantir o acesso à informação a uma ampla gama de usuários.

Isto se deve ao fato de o indexador concentrar seus esforços em todo o processo, tentando compatibilizar, em termos de recuperação da informação, demandas informacionais altamente especializadas e sofisticadas com aquelas consideradas, de certa forma, ainda pueris no que concerne à expressão de suas demandas por informações. A ação do bibliotecário visa criar as condições necessárias à identificação e ao acesso às unidades informacionais em seus diversos níveis. $E$ esse movimento requer uma sagacidade que vai além do caráter técnico da representação informacional.

Um dos exemplos mais emblemáticos deste esforço no contexto digital é o projeto Dublin Core Metadata Initiative (http://uk.dublincore.org/) que estimula a normalização, a gestão humana de informações em contextos digitais e a criação de consensos de caráter internacional em torno da organização da informação. Essa iniciativa demonstra que a automação geral do processo de representação e recuperação da informação não garante por si só o acesso informacional especializado.

Atualmente, verifica-se, como já explicitado por Chartier (2002), que o contexto eletrônico ainda não foi capaz de criar uma nova lógica de leitura que suplante por completo as práticas de leitura consolidadas historicamente. Nesse sentido, a permanência e relevância dos profissionais da leitura, tais como o bibliotecário-indexador, se mostra cada vez mais evidente.

\section{Considerações finais}

A partir do contexto acima apresentado, torna-se possível percebermos que as contribuições da estética da recepção para a ampliação do quadro explicativo das práticas de leitura do bibliotecárioindexador colocam em xeque a idéia de automatização dos processos de 
representação da informação $e$, ao mesmo tempo, sugerem que o processo de formação desses profissionais incorpore a idéia de apropriação informacional no desempenho de sua atividade profissional.

A anunciada e desejada isenção nos processos de representação da informação ainda continua a orientar os processos de formação acadêmica. Entretanto, os limites naturais de realização dessa ação são de tal ordem que, o ideal seria trabalhar com a idéia de leitor implícito apresentada por Iser, visto que tal perspectiva tornaria os processos de formação para as atividades de representação informacional menos áridos e desumanizados.

As concepções de horizonte de expectativa, efeito e emancipação também se apresentam como indispensáveis ao movimento de manipulação da informação para fins de disseminação em sistemas de recuperação informacional. São elementos que nos auxiliam a compreender as dimensões de uma ciência social aplicada, como o é a ciência da informação. Neste contexto, a idéia de aplicação não deve suplantar, de forma alguma, os elementos humanos contidos nessa amálgama de colaborações intelectuais.

Se conseguirmos dar a este movimento a agilidade e as articulações necessárias, poderemos vislumbrar um contexto em que a ação dos profissionais da leitura, e suas múltiplas intervenções, serão capazes de criar as condições para que tanto os leitores intermediários, quantos os finais, possam conduzir os seus gestos de leitura e de produção de significados de modo coerente.

Neste sentido, o novo ambiente poderá proporcionar aos integrantes dos distintos grupos que lidam com a informação, a possibilidade de examinar criticamente o alcance dos discursos por eles permutados nos modernos contextos de comunicação, mediação e recepção.

\section{Referências}

BARTHES, Roland. O rumor da língua. São Paulo: Brasiliense, 1998.

BARTHES, Roland; COMPGNON, Antoine. Leitura. In: Enciclopédia Einaudi. Porto: Imprensa Nacional/Casa da Moeda, 1987. v.11, p. 184-206.

BENJAMIN, Walter. O narrador: observações sobre a obra de Nikolai Leskov. In: BENJAMIN, Walter. [et al]. Os Pensadores. São Paulo: Abril Cultural, 1980. p. 57-74.

CAVALLO, Guglielmo; CHARTIER, Roger. História da leitura no mundo ocidental. São Paulo: Ática, 1992. 2v.

CERTEAU, Michel. A invenção do cotidiano. Petrópolis: Vozes, 1994. 2 v.

CHARTIER, Anne-Marie; HÉBRARD, Jean. A invenção do cotidiano: uma leitura, usos. Proj. História, São Paulo, n.17, p. 29-44, nov. 1998.

CHARTIER, Roger. (Org.) Práticas da leitura. São Paulo: Estação Liberdade, 1996. 
CHARTIER, Roger. A aventura do livro: do leitor ao navegador, conversações com Jean Lebrun. São Paulo: UNESP / Imprensa Oficial do Estado, 1999.

CHARTIER, Roger. A ordem dos livros: leitores, autores e bibliotecas na Europa entre os séculos XIV e XVII. 2 ed. Brasília: UNB, 1998.

CHARTIER, Roger. As representações do escrito. In: Formas e sentido, cultura escrita: entre distinção e apropriação. Campinas: Mercado de Letras / Associação de Leitura do Brasil, 2003. p. 17-48.

CHARTIER, Roger. Os desafios da escrita. São Paulo: Ed. UNESP, 2002.

COMPAGNON, Antoine. O demônio da teoria: literatura e senso comum. Belo Horizonte: UFMG, 2001. (Iluminuras; 41).

JAUSS, Hans Robert; LIMA, Luiz Costa. A Literatura e o leitor: textos de estetica da recepção. Rio de Janeiro: 1979. 213p.

JAUSS, Hans Robert. Pour une esthetique de la reception. Paris: Gallimard, 1990. 305p.

HAVELOCK, Erick. A revolução da escrita na Grécia e suas conseqüências culturais. São Paulo: UNESP; Rio de Janeiro: Paz e Terra, 1996.

ISER, Wolfgang. $O$ ato da leitura: uma teoria do efeito estético. São Paulo: Ed. 34, 1996. 2v.

LIMA, Luiz Costa. (Org.). A literatura e o leitor: textos de estética da recepção. 2 ed. rev. ampl. Rio de Janeiro: Paz e Terra, 2002.

MARTINS, Maria Helena. O que é leitura. 19 ed. São Paulo: Brasiliense, 2005. (Primeiros Passos; 74).

RICOEUR, Paul. Mundo do texto e mundo do leitor. In: Tempo e narrativa. Campinas: Papirus, 1997. v. 3, p. 273-314.

STEINER, George. Nenhuma paixão desperdiçada: ensaios. Rio de Janeiro: Record, 2001.

ZILBERMAN, Regina. Estética da recepção e história da literatura. São Paulo: Ática, 1989. (Fundamentos; 41).

ZILBERMAN, Regina. Fim do livro, fim dos leitores? São Paulo: SENAC, 2001. (Ponto Futuro; 3). 